\title{
Prevalence of Myofascial Trigger Points of Gastrocnemius in Dancers Padmaja Guruprasad ${ }^{1}$, Mrudula Sangaokar ${ }^{2}$, Tushar Palekar ${ }^{1}$ \\ ${ }^{1-3}$ Dr. D. Y. Patil College of Physiotherapy, Pune, Maharashtra, India \\ ${ }^{2}$ Musculoskeletal Department, Dr. D. Y. Patil College of Physiotherapy, Pune, Maharashtra, India
}

\begin{abstract}
Myofascial trigger points are hyperirritable spot which is usually a taut band of skeletal muscle, which is painful on compression and give rise to musculoskeletal dysfunction. Gastrocnemus muscle being the main muscle of mobility and stabilty in dancers. Due to this constant use of this muscle in various dance forms and the fatigue caused, it may cause trigger points.
\end{abstract}

\section{Objective}

1. To study the occurrence of trigger points in dancers.

2. To study prevalence of trigger points in various dance forms and finding out which dance form dancers have high prevalence for trigger point.

3. To study the correlation of presence of trigger point and strength of the gastrocnemius muscle.

\section{Materials and Methodology}

This is an observational study comprising of 100 samples who were trained dancers. Dancers of bharatnatayam, kathak and contemporary form were included and were palpated for trigger points, which were then presented in tabular and graphical manner.

\section{Results and Conclusion}

Results showed $52 \%$ have trigger point in gastrocnemius and $48 \%$ did not have trigger point in gastrocnemius. Out of the 3 dance forms selected, bharatnatayam dancers showed more prevalence of trigger point of gastrocnemius.

Keywords : Trigger Points, Gastrocnemius, Dancers, Bharatnatyam, Kathak, Contemporary Dancers.

\section{INTRODUCTION}

Dance is a form that is generally referred to movement of the body, usually rhythmic and to music, used as a form of expression, social interaction or presented in a spiritual or performance setting. It not only involves flexibility and body movement, but also physics of the body. If proper physics is not taken into consideration, injuries may occur.
World Health Organization (WHO) defined dance injuries as "a physical condition that causes pain and discomfort resulting in limitation, restriction or cessation in participation in dance."

Dance related injuries are usually a result from inherent biomechanical factors, environmental and training issues as well as technical competence. Overuse injuries account for $60-76 \%$ of all dance injuries affect the lower extremities. The most common locations for injuries are ankles, lower leg/ 
calves, usually caused by overuse, muscle strains and sprain. Due to overuse of gastrocneumius and soleus muscle (calf muscles) in dancers as they are the chief muscles in the lower limb prevalence of injury, pain, cramps etc. are very common. One of the main cause of calf pain and cramps are the myofascial trigger point. Trigger points are classified as being active or latent, depending on their clinical characteristics. An active trigger point causes pain at rest. It is tender to palpation with a referred pain pattern Trigger points are common in gastrocnemius muscle due to physical overload and mispositioning of the foot. In ballet dancers due to on pointe position, demi pointe position there is constant plantarflexion. In Bharatanatyam, the constant tapping of the feet and constant pressure on the muscle causes strain and cramps. In kathak, there is constant tapping of the feet for prolonged time may cause strain, pain and cramps In contemporary dancers, constant jumping, fast movements may also cause pain and cramps.

\section{METHODS AND MATERIAL}

Study location : Dances Classes around Pimpri was taken as the study place.

Sampling method : Purposeful sampling was done.100 dancers were selected for palpation of calf. Age group selected were 18-40 years old. People with recent lower limb fracture, ankle sprains, knee injuries, lumbar radiculopathy, lower limb metal implants were excluded from this study.

Data collection: Dancers of three dancers (Bharatanatyam, kathak, contemporary dancers) with history of calf cramps were selected and where palpated for trigger points on both medial and lateral heads for gastrocnemius. Along with palpation of trigger point, strength was assessed using manual muscle testing of gastrocnemius muscle.

\section{RESULTS AND DISCUSSION}

In this study, out of 100 dancers, 52 dancers showed the presence of trigger points of gastrocnemius muscle in dancers of various dance forms.

\begin{tabular}{|c|c|}
\hline $\begin{array}{c}\text { TRIGGER } \\
\text { POINT }\end{array}$ & PREVALENCE \\
\hline PRESENT & 52 \\
\hline ABSENT & 48 \\
\hline
\end{tabular}

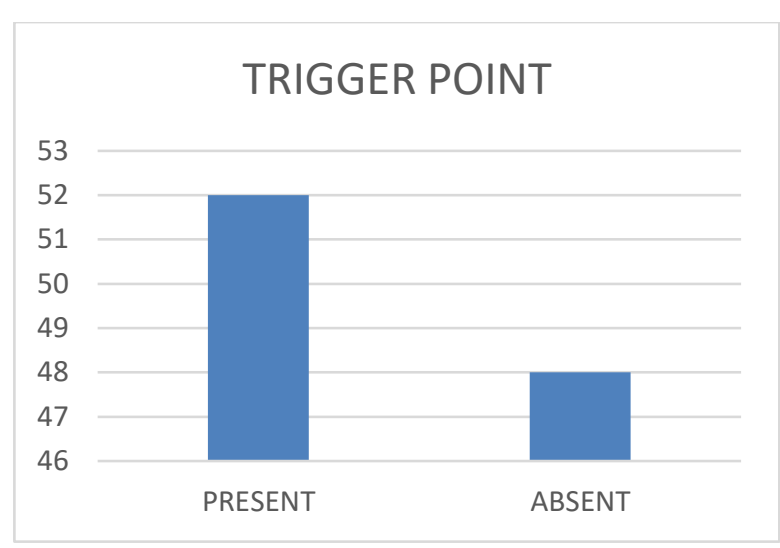

Fig 1. shows the prevalence of trigger points in gastrocnemius in dancers.

Out of the 100 dancers from all the three forms, there was a high prevalence of trigger points in bharatanatyam dancers $(n=20)$, followed by contemporary dancers $(\mathrm{n}=18)$ and then kathak dancers $(\mathrm{n}=14)$.

\begin{tabular}{|l|c|}
\hline DANCE FORM & $\begin{array}{l}\text { TRIGGER POINT } \\
\text { PRESENT IN NO. OF } \\
\text { DANCERS }\end{array}$ \\
\hline $\begin{array}{l}\text { BHARATNATY } \\
\text { AM }\end{array}$ & 20 \\
\hline KATHAK & 14 \\
\hline $\begin{array}{l}\text { CONTEMPORA } \\
\text { RY }\end{array}$ & 18 \\
\hline
\end{tabular}




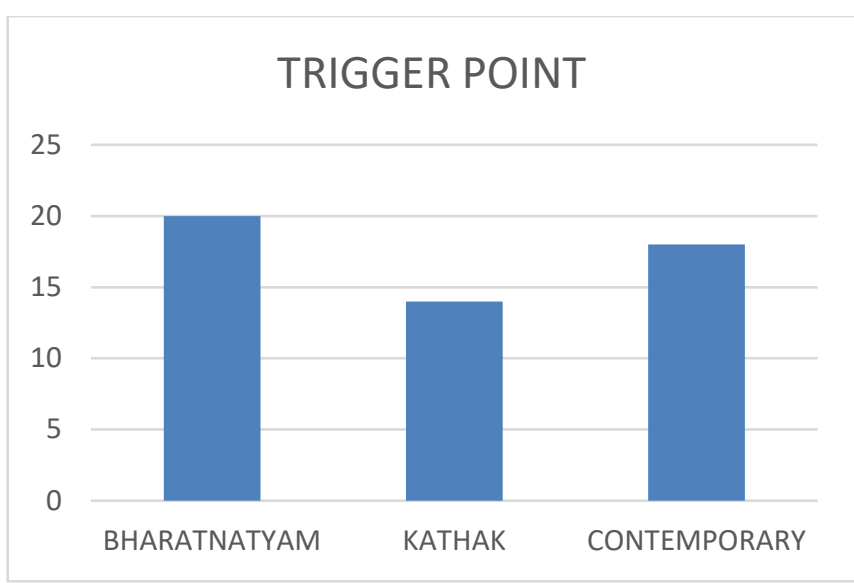

Fig 2. shows the prevalence of trigger point in all the three dance forms

According to our study, the dancers felt maximum pain at intensity of 5.(n=18). The pain ranged from 2-7 on the VAS

\begin{tabular}{|l|l|}
\hline $\begin{array}{l}\text { PAIN ON } \\
\text { VAS }\end{array}$ & NO OF STUDENTS \\
\hline 2 & 6 \\
\hline 3 & 13 \\
\hline 4 & 5 \\
\hline 5 & 18 \\
\hline 6 & 8 \\
\hline 7 & 2 \\
\hline
\end{tabular}

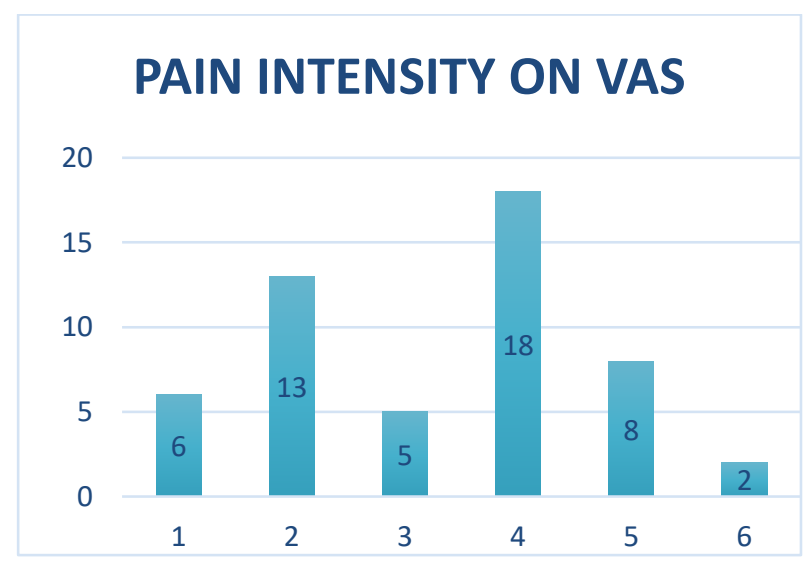

Fig 3. shows the pain on VAS

In our study, there was no significant correlation between strength and trigger point presence. Most of the dancers showed the muscle strength $4+$.

\begin{tabular}{|l|l|}
\hline MMT & NO. OF DANCERS \\
\hline 4 & 14 \\
\hline $4+$ & 54 \\
\hline 5 & 32 \\
\hline
\end{tabular}

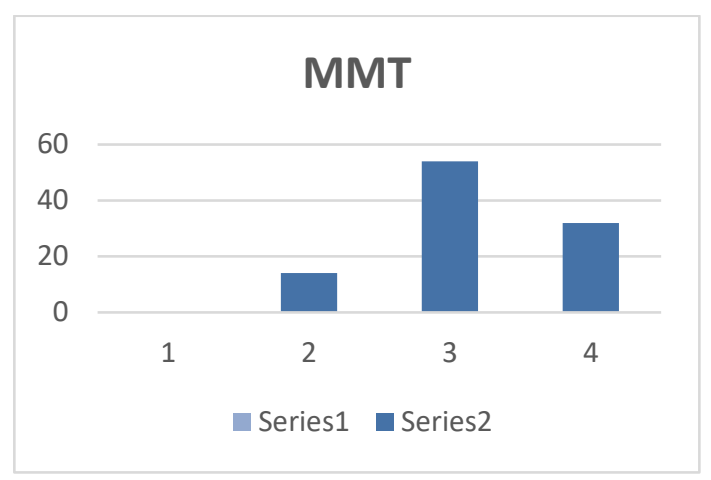

Fig.4 shows the MMT in all dancers.

\section{IV.DISCUSSION}

The aim was to study the prevalence of myofascial trigger point in gastrocnemius muscle in dancers who practice regularly. Overuse injuries account for $60-76 \%$ of all dance injuries affect the lower extremities. The most common locations for injuries are ankles, lower leg/ calves, usually caused by overuse, muscle strains and sprain. [1] Due to overuse of gastrocnemius and soleus muscle (calf muscles) in dancers as they are the chief muscles in the lower limb prevalence of injury, pain, cramps etc. are very common. One of the main cause of calf pain and cramps are the myofascial trigger point. In Bharatanatyam, the constant tapping of the feet and constant pressure on the muscle causes strain and cramps. In kathak, there is constant tapping of the feet for prolonged time may cause strain, pain and cramps. In contemporary dancers, constant jumping, fast movements may also cause pain and cramps. [3] In dancers, gastrocnemius is the main muscle for mobility as well as stability. Due to this continuous overloading on the muscle causes 
fatigue. Fatigue has shown to be a contributing factor for trigger points. Overuse injury that often leads to calf pain in dancers. There is evidence that musculoskeletal injury is an important health issue for dancers at all skill levels. There is a high prevalence and incidence of lower extremity, with soft tissue and overuse injuries predominating. [5] Studies have shown that trigger point is developed when the muscle has been in continuous shortened state, with the knee bent and foot plantar flexed. In Bharatanatyam and contemporary dance form it is seen that the above-mentioned position of the leg is assumed for long durations. This study also shows that Bharatanatyam dancers have more prevalence of gastrocnemius trigger points followed by contemporary and kathak dancers. Studies show that on identification of trigger point shows 4 major sign and symptoms: taut band, hypersensitive spot, local twitch response and jump sign. In this study majority of the samples with trigger point gave positive sign for local twitch response. This local twitch response is caused because the damaged tissue releases bradykinin, serotonin, protons and prostaglandins. Due to this continuous stimulation of nociceptors and release of the above substances causes persistent pain. [6] Studies have shown that there is rarely any presentation of muscle weakness associated with the presence of trigger points. This study also confirms that there was no presentation of weakness of the gastrocnemius muscle in all the three forms of dancers. Muscle weakness is caused due to accumulation of inorganic metabolites at the muscular level that inhibits cross bridge formation causing muscle fatigue and muscle weakness. [7].

\section{v. CONCLUSION}

The study shows that there is $52 \%$ of dancers who have trigger point present. Amongst the three type of dancers, Bharatanatyam dancers showed more present of prevalence of trigger point of the gastrocnemius. There was no change in the muscle strength in relation to the presence of trigger point.

\section{REFERENCES}

[1]. Simons DG, Travell JG, Simons LS. Travell \& Simons' Myofascial pain and dysfunction: the trigger point manual. 2nd ed. Baltimore: Williams \& Wilkins, 1999:5.

[2]. The prevalence of latent myofascial trigger points and diagnostic criteria of the triceps surae and upper trapezius: a cross sectional study Rob Grieve a, , Sue Barnett a, Nikki Coghill b, Fiona Cramp

[3]. Roshini Prakash: Musculoskeletal effects and injury risk in collegiate Indian classical and ballet dancers

[4]. Dr. Laura Perry: Gastrocnemius Trigger Points: The Calf Cramp Trigger Points, February 6, 2013

[5]. Musculoskeletal Injuries and Pain in Dancers: A Systematic Review Cesar A. Hincapié, DC, MHSc, Emily J. Morton, DC, FCCS(C), J. David Cassidy, $\mathrm{PhD}$, DrMedSc

[6]. Biochemicals Associated with Pain and Inflammation are Elevated in Sites Near to and Remote from Active Myofascial Trigger Points Jay P. Shah, MD, Jerome V. Danoff, PhD, PT, Mehul J. Desai, MD, Sagar Parikh, BA, Lynn Y. Nakamura, MD, Terry M. Phillips, PhD, DSc, Lynn H. Gerber, MD.

[7]. Accelerated Muscle Fatigability of Latent Myofascial Trigger Points in Humanspme_1416 957..964 Hong-You Ge, MD, PhD, Lars ArendtNielsen, Dr. Med. Sci., PhD, and Pascal Madeleine, Dr. Med. Sci., PhD

Cite this article as : Padmaja Guruprasad, Mrudula Sangaokar, Tushar Palekar, "Prevalence of Myofascial Trigger Points of Gastrocnemius in Dancers", International Journal of Scientific Research in Science and Technology (IJSRST), Online ISSN : 2395-602X, Print ISSN : 2395-6011, Volume 6 Issue 2, pp. 134-137, March-April 2019. Available at doi : https://doi.org/10.32628/IJSRST196179

Journal URL : http://ijsrst.com/IJSRST196179 